Moch. Shofwan dan Farida Nur'Aini: Zonasi Sebaran Pencemaran Air Berbasis Persepsi Masyarakat di Kawasan Bencana Lumpur Kabupaten Sidoarjo

\title{
ZONASI SEBARAN PENCEMARAN AIR BERBASIS PERSEPSI MASYARAKAT DI KAWASAN BENCANA LUMPUR KABUPATEN SIDOARJO
}

\author{
Moch. Shofwan ${ }^{1)}$ dan Farida Nur'Aini ${ }^{1)}$ \\ ${ }^{1)}$ Program Studi Perencanaan Wilayah dan Kota; Fakultas Teknik Sipil dan Perencanaan (FTSP) \\ Universitas PGRI Adi Buana Surabaya \\ Email : shofwan.moch@gmail.com
}

\begin{abstract}
Abstrak
Bencana lumpur di Kabupaten Sidoarjo merupakan peristiwa alam yang tergolong risikonya tinggi. Dipilihnya lokasi tersebut karena peristiwa ini memberikan dampak yang signifikan terhadap perubahan fisik yang ada di kawasan tersebut. Tujuan dari penelitian ini yaitu melakukan pemetaan pencemaran air berdasarkan persepsi masyarakat. Adapun untuk mencapai tujuan ini maka diperlukan beberapa tahapan yaitu (1) analisis kondisi pencemaran air berdasarkan persepsi masyarakat, (2) analisis sebaran keruangan pencemaran air di kawasan bencana lumpur. Pendekatan penelitian ini menggunakan deskriptif kuantitatif, kualitatif, dan eksploratif. Metode pengumpulan data pada penelitian ini menggunakan data primer dan data sekunder. Adapun metode analisis yang digunakan dibagi menjadi dua tahapan yaitu (1) analisis deskriptif kualitatif berdasarkan kondisi pencemaran air, dan (2) analisis spasial terkait kondisi pencemaran air. Kondisi pencemaran air berdasarkan persepsi masyarakat dilapangan didapatkan hasil bahwa pencemaran air terdapat di kawasan bencana lumpur lapindo di desa-desa pada tiga kecamatan (Porong, Tanggulangin, dan Jabon). Pencemaran air dapat dilihat dari perubahan warna, rasa, dan bau yang dilihat dari sumur warga, tambak, dan sungai. Hasil dari pemetaan kondisi pencemaran air secara spasial didapatkan bahwa pencemaran air terkonsentrasi di zona I dan II, disebabkan karena lokasi desa-desa tersebut sangat dekat dengan luapan lumpur lapindo.
\end{abstract}

Kata Kunci : Pemetaan, Pencemaran air, Lumpur.

\begin{abstract}
Disaster mudflow in Sidoarjo regency is a natural event that is considered high risk. The location is chosen because it has a significant impact on the physical changes that exist in the region. The purpose of this research is to mapping water pollution based on community perception. As for achieving this goal, it needs several stages: (1) analysis of water pollution condition based on public perception, (2) analysis of spatial distribution of water contamination in mudflow disaster area. This research approach using descriptive quantitative, qualitative, and eksploratif. Data collection methods in this study using primary data and secondary data. The analysis method used is divided into two stages: (1) qualitative descriptive analysis based on water pollution condition, and (2) spatial analysis related to water pollution condition. The condition of water pollution based on community perception in the field showed that water pollution was found in Lapindo mudflow disaster area in villages in three sub-districts (Porong, Tanggulangin, and Jabon). Water pollution can be seen from the change of color, taste, and smell seen from residents' wells, ponds and rivers. The result of spatial water spatial mapping is found that water pollution is concentrated in zones I and II, due to the location of these villages very close to the lapindo mudflow.
\end{abstract}

Keywords : Mapping, Water Pollution, Mudflow. 


\section{PENDAHULUAN}

Bencana adalah peristiwa atau rangkaian peristiwa yang dapat mengancam dan mengganggu kehidupan dan penghidupan masyarakat yang terjadi secara tiba-tiba maupun perlahan, dan disebabkan baik oleh faktor alam dan/atau faktor non-alam maupun faktor manusia, sehingga mengakibatkan kematian, luka-luka, kehilangan tempat tinggal, kerugian ekonomi, kerusakan sistem pemerintahan, efeknya terhadap kesehatan, serta dampak psikologis (UU No. 24 Tahun 2007; Twigg, 2004; Carter, 1991).

Terdapat 12 desa dari tiga kecamatan yang terendam dan terdampak oleh lumpur Lapindo yang sampai saat ini genangan lumpur terus bertambah terutama disekitar pusat semburan lumpur, sehingga tanggul penahan lumpur sudah beberapa kali jebol akibat luapan lumpur yang tidak dapat lagi dibendung (Akbari et al, 2011), di antaranya Kelurahan Siring, Jatirejo, Mindi, Glagaharum dan Renokenongo, (Kecamatan Porong); Desa Ketapang, Kalitengah, Kedungbendo dan Gempolsari (Kecamatan Tanggulangin); Desa Pejarakan, Kedungcangkring dan Desa Besuki (Kecamatan Jabon) (BP- BPLS, 2008). Pencemaran air tanah merupakan salah satu dampak yang diakibatkan oleh luapan lumpur, beberapa desa yang ada di kawasan bencana lumpur kondisi eksisting airnya mengalami pencemaran yang diindikasikan dengan berubahnya warna, bau, dan rasa.

\section{METODE}

\section{Unit Analisis}

Unit analisis dalam penelitian ini adalah 12 desa terdampak lumpur dari total 53 desa di tiga kecamatan meliputi 19 desa di Kecamatan Porong, 19 desa di Kecamatan Tanggulangin, dan 15 desa di Kecamatan Jabon. Wilayahwilayah desa di tiga kecamatan terdampak lumpur memiliki variasi lingkungan fisik dan posisi geografis yang berbeda-beda, sehingga potensi pencemaran airnya juga bervariasi.

Metode pengumpulan data merupakan salah satu prosedur untuk mendapatkan kondisi riil pada suatu penelitian. Pada tahap pengumpulan data dilakukan pemahaman terhadap karakteristik dari variabel-variabel yang akan diamati pada wilayah studi.

Metode pengumpulan data ditinjau dari sumber data yang akan diamati, yaitu :

1. Survei Data Primer

Survei data primer merupakan survei yang dilakukan dengan turun langsung ke lapangan atau obyek studi. Dalam pengumpulan data primer dilakukan dengan dua cara pendekatan :

\section{a. Kuesioner}

Kuesioner sebagai alat pengambilan data yang berbentuk pertanyaanpertanyaan yang mengacu pada variabel penelitian.

b. Observasi

Pengamatan dengan menggunakan indera penglihatan yang tidak mengajukan pertanyaan-pertanyaan. Wawancara

Wawancara dilakukan sebagai kegiatan untuk mendapatkan bahan informasi yang berfungsi untuk membahas permasalahan penelitian dengan tetap mengacu pedoman arah penelitian.

2. Data Sekunder

Survei sekunder adalah survei yang dilakukan dengan tidak turun langsung ke lapangan melainkan mengumpulkan data atau informasi dari beberapa sumber seperti instansi terkait dan literatur. Data sekunder biasanya telah tersusun dalam bentuk dokumen-dokumen.

\section{Variabel dan Teknik Analisis}

Variabel yang akan diteliti yaitu untuk menjawab rumusan masalah yang telah diuraikan. Berikut dapat dilihat pada tabel 1 .

Tabel 1. Variabel Penelitian

\begin{tabular}{|c|c|c|c|c|}
\hline Tujuan & Sub Variabel & Parameter & Sumber & Teknik Analisis \\
\hline $\begin{array}{l}\text { Menganalisis } \\
\text { kondisi } \\
\text { pencemaran air } \\
\text { berdasarkan } \\
\text { persepsi } \\
\text { masyarakat }\end{array}$ & $\begin{array}{ll}- & \text { Kondisi } \\
& \text { warna } \\
\text { - } & \text { Kondisi bau } \\
\text { - } & \text { Kondisi rasa }\end{array}$ & $\begin{array}{l}\text { Kondisi } \\
\text { pencemaran air }\end{array}$ & $\begin{array}{ll}\text { - } & \text { Kuesioner } \\
\text { - } & \text { Observasi } \\
\text { - } & \text { Wawancara }\end{array}$ & $\begin{array}{l}\text { Deskriptif } \\
\text { Kualitatif, } \\
\text { Kuantitatif, } \\
\text { Eksploratif. }\end{array}$ \\
\hline $\begin{array}{l}\text { Menganalisis } \\
\text { sebaran }\end{array}$ & $\begin{array}{ll}\text { - } & \text { Jarak } \\
& \text { (interpolasi) }\end{array}$ & $\begin{array}{l}\text { Zonasi dan } \\
\text { Interpolasi }\end{array}$ & $\begin{array}{l}\text { - Data spasial } \\
\text { dengan }\end{array}$ & $\begin{array}{ll}\text { - } & \text { Analisis } \\
& \text { Spasial }\end{array}$ \\
\hline
\end{tabular}


Moch. Shofwan dan Farida Nur'Aini: Zonasi Sebaran Pencemaran Air Berbasis Persepsi Masyarakat di Kawasan Bencana Lumpur Kabupaten Sidoarjo

\begin{tabular}{lclll}
\hline \multicolumn{1}{c}{ Tujuan } & Sub Variabel & Parameter & Sumber & Teknik Analisis \\
\hline keruangan & - & Zonasi & & menggunaka \\
pencemaran air & (buffering) & & n sistem & \\
& & informasi & \\
& & geografis & \\
\hline
\end{tabular}

\section{HASIL DAN PEMBAHASAN}

Terdapat 12 desa dalam 3 kecamatan yang terkena dampak dari bencana lumpur lapindo, dari 12 desa tersebut 3 diantaranya sudah tenggelam total yaitu Desa Jatirejo, Kedungbendo, dan Renokenongo, dan ada 9 desa lainnya masih belum tenggelam total. Berikut gambaran karakteristik wilayah masing-masing kecamatan.

\section{1) Kecamatan Porong}

Kecamatan Porong merupakan salah satu kecamatan yang terkena dampak dari bencana lumpur lapindo, diantara desa dan kelurahan yang terkena dampak adalah Desa Glagaharum.

A. Desa Glagaharum

1. Demografi

Desa Glagaharum memiliki jumlah penduduk yang cukup tinggi, meskipun desa tersebut merupakan salah satu desa yang terdampak lumpur lapindo namun jumlah penduduk yang masih tinggal didesa ini jumlahnya masih tinggi.

2. Lingkungan

Desa Glagaharum merupakan desa yang paling dekat dengan pusat semburan lumpur lapindo, wilayah desa ini juga hanya tersisah separuh, karena separuh dari desa tersebut sudah terendam oleh lumpur lapindo. Karena desa ini yang paling dekat dengan pusat semburan lumpur maka hampir semua warganya menjual tanah dan rumah mereka karena khawatir akan datangnya semburan lumpur lapindo yang baru. Namun kondisi eksistingnya masih banyak warga yang bertahan karena masih berat meninggalkan desa yang menjadi tempat bersejarah.

Pada umumnya Desa Glagaharum mempunyai banyak sumber air namun setelah terjadinya bencana Lumpur Lapindo, ada beberapa sumber air yang terganggu dan tercemar. Di karenakan Desa Glagaharum adalah desa yang paling dekat dengan semburan lumpur lapindo, Seperti keadaan sungai pada desa ini sangat buruk hampir $80 \%$ keadaan sungai tercemar oleh sampah dan limbah karena aliran sungai yang semakin dangkal dan sempit maka jika sedang pada musim hujan desa ini mengalami kebanjiran. Begitu pula dengan keadaan sumur pada desa ini tercemar, sumur pada desa ini memiliki kandungan minyak sehingga jika dilihat dari permukaan terlihat ada genangan minyak yang bercampur dengan air.
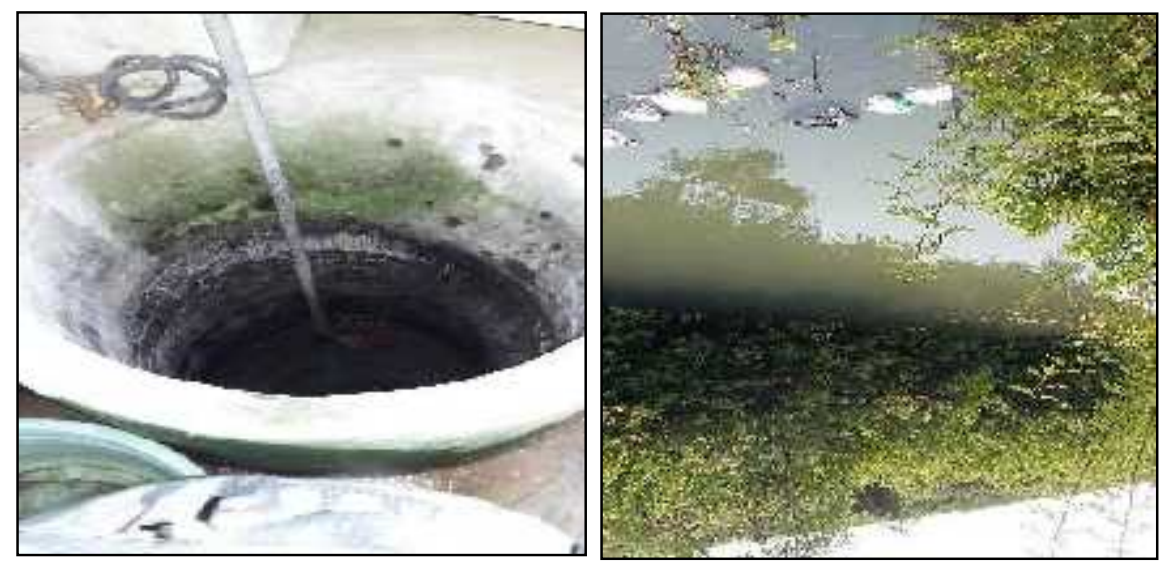

Gambar 1. Kondisi Sumur dan Sungai Tercemar 


\section{2) Kecamatan Tanggulangin}

Pada Kecamatan ini terdapat Desa Kalitengah, yang wilayahnya terkena dampak dari luapan lumpur lapindo.

A. Desa Kalitengah

1. Demografi

Desa Kalitengah memiliki jumlah penduduk yang tinggi, jumlah penduduknya mencapai angka diatas 10.000 jiwa.

2. Lingkungan

Pada desa ini kondisi topografi tanahnya memiliki keadaaan yang baik dan bukan terletak pada daerah ketinggian namun jika masuk pada musim hujan, desa ini sering terjadi banjir karena desa tersebut tidak memiliki drainase yang baik karena sungai yang terletak pada desa tersebut sudah semakin dangkal dan tersumbat sampah. Dikarenakan aliran sungai dari beberapa desa mengalir pada desa ini dan sangat berpengaruh pada sumber airnya, masyarakat Desa Kalitengah sehari-hari menggunakan air PDAM untuk mencuci dan mandi sedangkan untuk minum dan masak masyarakat menggunakan air isi ulang atau beli di toko.

Desa Kalitengah adalah desa yang letaknya disebelah utara dari pusat semburan lumpur. Banyak akibat yang ditimbulkan seperti keadaan sumur yang kotor dan keruh karena tidak ada yang merawat.
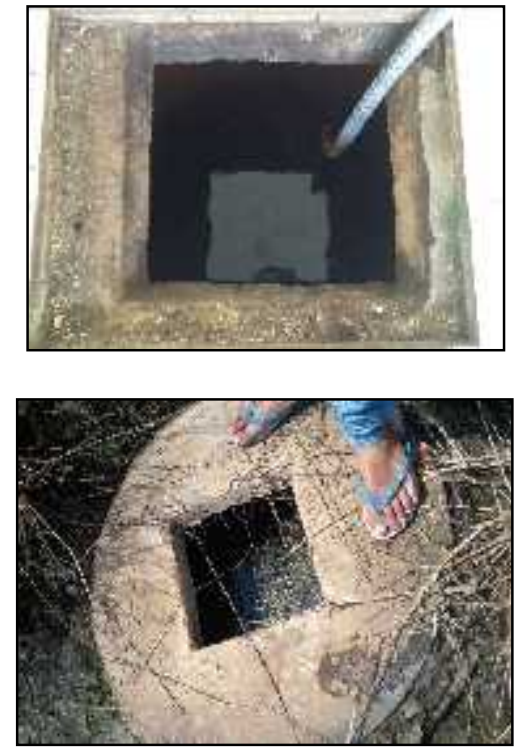

Gambar 2. Perbedaan Sumur yang terpakai dan tidak terpakai

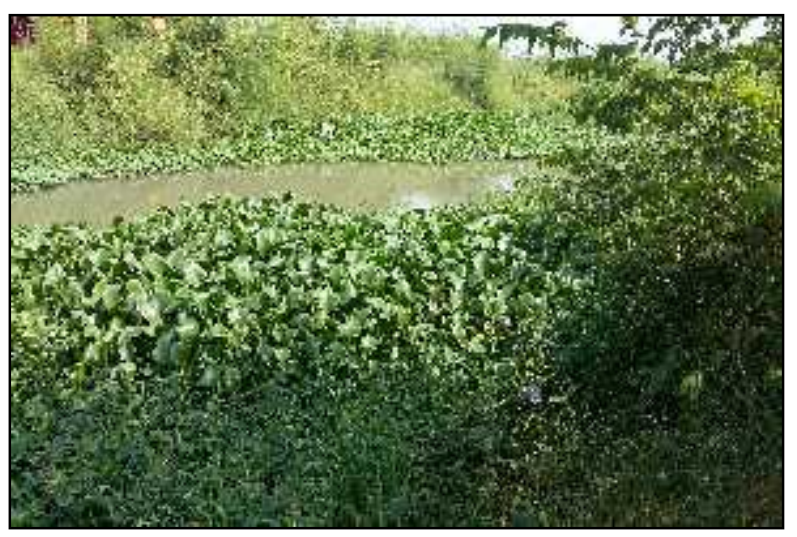

Gambar 3. Sungai di Desa Kalitengah

\section{3) Kecamatan Jabon}

Kecamatan Jabon juga merupakan salah satu kecamatan yang terkena dampak dari bencana lumpur lapindo.

A. Desa Pejarakan

1. Demografi

Desa Pejarakan memiliki jumlah penduduk yang cukup rendah, jumlah penduduknya mulai berkurang dari tahun ketahun karena sudah diberi ganti rugi sama pihak lapindo.

2. Lingkungan

Desa Pejarakan adalah desa yang bersebelahan dengan Desa Mindi, Desa Pejarakan juga sama seperti desa-desa lain disekitar lumpur lapindo yang mengalami banjir jika memasuki musim penghujan. Di desa ini juga masih banyak warganya yang masih bertahan dan tinggal disini namun ada beberapa sekolah yang sudah di non aktifkan dikarenakan bencana lumpur lapindo tersebut. Beberapa sumber air di desa ini meliputi sumur dan sungainya mengalami pencemaran.

\section{4) Pemetaan Sebaran Pencemaran Air}

Berdasarkan hasil penelitian, berikut hasil pemetaan spasial sebaran pencemaran air yang terdampak bencana lumpur lapindo dapat dilihat pada gambar berikut. 
Moch. Shofwan dan Farida Nur'Aini: Zonasi Sebaran Pencemaran Air Berbasis Persepsi Masyarakat di Kawasan Bencana Lumpur Kabupaten Sidoarjo

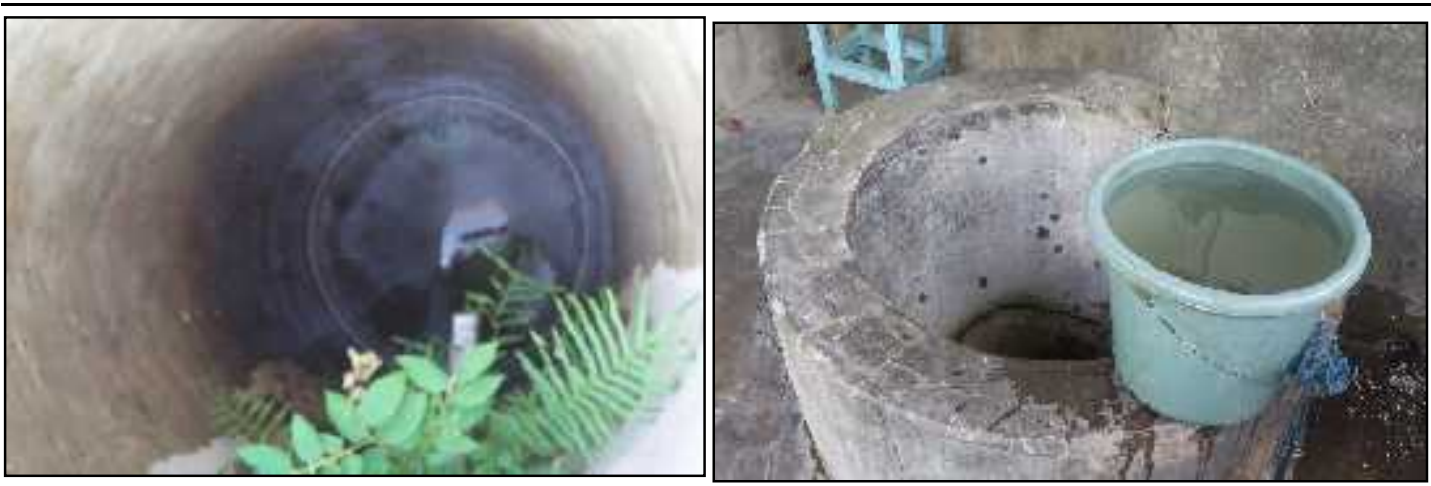

Gambar 4. Kondisi Sumur di Desa Pejarakan

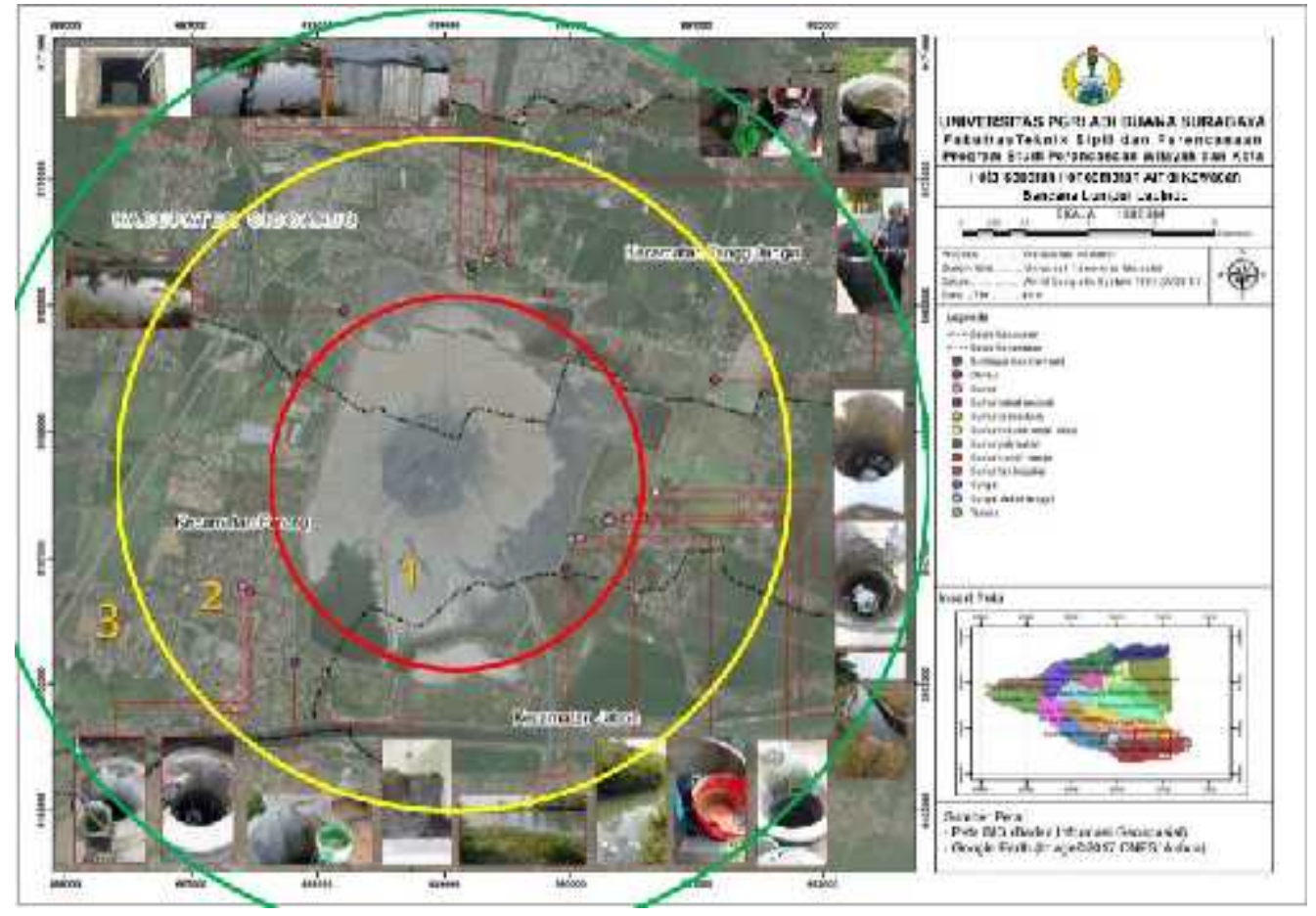

Gambar 5. Peta Sebaran Pencemaran Air

Berdasarkan Gambar 5. hasil dari pemetaan kondisi pencemaran air secara spasial didapatkan bahwa pencemaran air terkonsentrasi di zona I dan II, disebabkan karena lokasi desa-desa tersebut sangat dekat dengan luapan lumpur lapindo dan sebagai jalur pembuangan luapan lumpur dari kolam utama.

\section{KESIMPULAN}

Kondisi pencemaran air berdasarkan persepsi masyarakat dilapangan didapatkan hasil bahwa pencemaran air masih terdapat di kawasan bencana lumpur lapindo di desa-desa di tiga kecamatan (Porong, Tanggulangin, dan Jabon). Pencemaran air dapat dilihat dari perubahan warna, rasa, dan bau yang dilihat dari sumur warga, tambak, dan sungai.Hasil dari pemetaan kondisi pencemaran air secara spasial didapatkan bahwa pencemaran air terkonsentrasi di zona I dan II, disebabkan karena lokasi desa-desa tersebut sangat dekat dengan luapan lumpur lapindo dan sebagai jalur pembuangan luapan lumpur dari kolam utama.

\section{UCAPAN TERIMA KASIH}

Penelitian ini telah mendapatkan dukungan dari Dekan, Ketua Program Studi Perencanaan Wilayah dan Kota. Selain itu disampaikan ucapan terimakasih kepada LPPM UNIPA Surabaya atas dukungan dana yang diberikan kepada peneliti. 


\section{DAFTAR PUSTAKA}

Abidin, H.Z., Kusuma, M.A., Andreas, H., Gamal, M., Sumintadireja, P., 2009. GPS-Based Monitoring of Surface Displacements in the Mud Volcano Area, Sidoarjo, East Java.Springer. hal. 595-603.

Akbari, A.M. dan Teguh H., 2011. Perhitungan Volume Semburan dan Sebaran Lumpur Sidoarjo Dengan Citra Ikonos Bulan Juni, Agustus, Oktober 2011. Teknik Geomatika FTSP-ITS Surabaya.

Carter, N. 1991. Disaster Management: A Disaster Manager's Handbook, ADB, Manila.

Harmayani, KD dan IGM Konsukartha. 2007. Pencemaran Air Tanah Akibat Pembuangan Limbah Domestik di Lingkungan Kumuh. Jurnal Permukiman Natah Vol. 5 Nomor 2 Agustus Tahun 20017.

Muta'ali, L. 2012. Daya Dukung Lingkungan untuk Perencanaan Pengembangan Wilayah. Yogyakarta: Fakultas Geografi UGM.

Satyana, A.H. 2007. Bencana Geologi dalam "Sandhyâkâla" Jenggala dan Majapahit: Hipotesis Erupsi Gununglumpur Historis Berdasarkan Kitab Pararaton, Serat Kanda, Babad Tanah Jawi; Folklor Timun Mas; Analogi Erupsi LUSI; dan Analisis Geologi Depresi KendengDelta Brantas. Joint Convention Bali 2007. The $36^{\text {th }}$ IAGI, The $32^{\text {nd }}$ HAGI, and The $29^{\text {th }}$ IATMI. hal. 1-37.

Smith. K. dan Petley, D.N., 1992. Environmental Hazards: Assessing Risk and Reducing Disaster, , Routledge. London and Newyork.

Sugiyono, 2013. Metode Penelitian Kombinasi (Mixed Methods). Bandung: Alfabeta .

Tingay, M. 2010. Anatomy of the LUSI Mud Eruption, East Java. ASEG 2010. hal. 1-6

Twigg, J. 2004. Good Practice Review:Disaster Risk Reduction. Mitigation and preparedness in development and emergency programming. Humanitarian Practice Network (HPN), Overseas Development Institute, London.

UURI No. 24 Tahun 2007 tentang penanggulangan bencana, LNRI Tahun 2007 Nomor 66; TLNRI Nomor 4723Han, Z., Liu, D., dan Li, Q. (2013), "A Removal Mechanism for Organics and Nitrogen in Treating Leachate Using a Semi-Aerobic Aged Refuse Biofilter", Journal of Environmental Management, Vol. 114, hal. 336-342. 